\title{
Perdas no Processo de Ensilagem: Uma breve revisão
}

\author{
Losses in the silagem process: A brief review \\ Pérdidas em el processo de ensilaje: Uma breve reseña
}

Recebido: 05/04/2021 | Revisado: 12/04/2021 | Aceito: 15/04/2021 | Publicado: 28/04/2021

Bárbara Louise Pacheco Ramos

ORCID: https://orcid.org/0000-0001-5055-7120

Universidade Estadual do Sudoeste da Bahia, Brasil

E-mail: agro.barbara@ outlook.com

Aureliano José Vieira Pires

ORCID: https://orcid.org/0000-0002-4015-3445

Universidade Estadual do Sudoeste da Bahia, Brasil

E-mail: aurelianojvp@uesb.edu.br

Natan Teles Cruz

ORCID: https://orcid.org/0000-0001-8164-0429

Universidade Estadual do Sudoeste da Bahia, Brasil

E-mail: teles.nc@gmail.com

Adriane Pereira da Silva dos Santos

ORCID: https://orcid.org/0000-0001-6937-5984

Universidade Estadual do Sudoeste da Bahia, Brasil

E-mail: adrianezootec@gmail.com

Luiza Maria Gigante Nascimento

ORCID: https://orcid.org/0000-0001-6115-0684

Universidade Estadual do Sudoeste da Bahia, Brasil E-mail:1u_gigante@hotmail.com

Hugo Pereira Santos

ORCID: https://orcid.org/0000-0002-6516-5661 Universidade Estadual do Sudoeste da Bahia, Brasil

E-mail: hugo_pereirasantos@yahoo.com

Juan Mark Silva Amorim

ORCID: https://orcid.org/0000-0002-3598-2054

Universidade Estadual do Sudoeste da Bahia, Brasil E-mail: juanmjmark@gmail.com

\begin{abstract}
Resumo
A ensilagem é o principal processo de conservação de forragem, sendo bastante utilizada em períodos de baixa oferta de massa forrageira no pasto ou em sistemas mais intensivos da produção animal. Diversos fatores afetam a qualidade da silagem, tanto no momento da colheita quanto no período de armazenagem e abertura do silo, podendo ocasionar redução da qualidade nutritiva. Na conservação das forrageiras, é fundamental controlar as perdas de matéria seca para que teor nutritivo não reduza drasticamente. Há ainda outras perdas em forma de efluentes, que são produzidos por excesso de umidade; as perdas em forma de gases que são resultantes das reações fermentativas, produzindo dióxido de carbono na qual interfere diretamente na qualidade nutricional. Uma das maneiras de reduzir as perdas é a utilização de aditivos no processo da ensilagem, pois promoverá um ambiente adequado para produção do ácido lático e inibirá o crescimento de microrganismos deteriorantes. Desta forma, é evidente a importância de conhecer as perdas que estão relacionadas no processo da ensilagem, a fim de minimizá-las e obter como resultado uma silagem apropriada para o uso no sistema de produção animal.
\end{abstract}

Palavras-chave: Conservação de alimentos; Fermentação anaeróbica; Matéria Seca.

\begin{abstract}
Silage is the main forage conservation process, being widely used in periods of low supply of forage in the pasture or in more intensive systems of animal production. Several factors affect the quality of the silage, both at the time of harvest and in the period of storage and opening of the silo, which may cause a reduction in nutritional quality. In this forage conservation, it is essential to control dry matter losses so that the nutrient content does not drastically reduce. There are still other losses in the form of effluents, which are produced by excess humidity; losses in the form of gases resulting from fermentative reactions, producing carbon dioxide which directly interferes with nutritional quality. One of the ways to reduce losses is the use of additives in the silage process, as it will promote an adequate environment for the production of lactic acid and inhibit the growth of deteriorating microorganisms. Thus, it is evident the importance of knowing the losses that are related in the silage process, in order to minimize them and obtain as a result an appropriate silage for use in the animal production system.
\end{abstract}

Keywords: Food preservation; Anaerobic fermentation; Dry matter. 


\begin{abstract}
Resumen
El ensilaje es el principal proceso de conservación de forrajes, siendo ampliamente utilizado en períodos de escasa oferta de forrajes en el pasto o en sistemas más intensivos de producción animal. Varios factores inciden en la calidad del ensilado, tanto en el momento de la cosecha como en el período de almacenamiento y apertura del silo, lo que puede provocar una reducción de la calidad nutricional. En esta conservación de forrajes es fundamental controlar las pérdidas de materia seca para que el contenido de nutrientes no se reduzca drásticamente. Aún existen otras pérdidas en forma de efluentes, que se producen por exceso de humedad; pérdidas en forma de gases resultantes de reacciones fermentativas, produciendo dióxido de carbono que interfiere directamente con la calidad nutricional. Una de las formas de reducir las pérdidas es el uso de aditivos en el proceso de ensilado, ya que promoverá un ambiente adecuado para la producción de ácido láctico e inhibirá el crecimiento de microorganismos deteriorantes. Así, se evidencia la importancia de conocer las pérdidas que se relacionan en el proceso de ensilaje, con el fin de minimizarlas y obtener como resultado un ensilaje adecuado para su uso en el sistema de producción animal.
\end{abstract}

Palabras clave: Conservación de alimentos; Fermentación anaeróbica; Materia seca.

\title{
1. Introdução
}

Com o aumento da competitividade mundial no sistema cárneo e leiteiro, a utilização de forragem conservada cresce a cada ano promovendo avanços e equilíbrio para a produção animal. A sua principal utilização é em períodos secos de baixa oferta de forragem pelas pastagens, momento em que o pasto não oferece a quantidade de nutrientes necessários para os animais em produção. A conservação de forragens é um método que oferece a oportunidade de conservar alimentos perdendo o mínimo do seu valor nutritivo, ainda elevando o período de sua utilização, ou seja, os processos envolvidos na conservação permitem que o alimento seja armazenado e utilizado em períodos mais longos.

Dentre as formas de conservação da forragem, a ensilagem é o principal método utilizado nos sistemas produtivos. A técnica é baseada no processo fermentativo, onde a ausência do oxigênio favorece a produção do ácido lático, produto resultante da fermentação que beneficia a massa verde picada em uma massa fermentada e apropriada para o consumo animal. Essa técnica constitui-se em uma estratégia viável para a alimentação de ruminantes em todo o território tropical, sendo vantajosa por ser simplista e eficiente (Teixeira et al., 2009). Entretanto, é necessário cuidado com o valor nutritivo desse alimento.

A produção de uma forragem de qualidade e nutritiva é um desafio, principalmente em regiões tropicais na qual estão sob efeito da sazonalidade, entretanto, o manejo inadequado da planta forrageira no campo torna-se um fator influenciador nessa qualidade. Desta forma, para obter uma silagem considerada de qualidade, é necessário que ela seja colhida em um ponto ótimo, e que o material retirado percorra por uma sequência de fases na fermentação. Essas etapas são importantes para que haja um mínimo de perdas possível ao longo desse processo, na forma de nutrientes, gases e efluente (Fernandes et al., 2016).

No processo da ensilagem ocorrem as perdas desde a colheita da planta forrageira até o momento de abertura do silo. Diversos fatores podem ocasionar perdas nesse processo, sendo eles: má compactação do material, colheita da massa forrageira fora do ponto ideal, bem como uma vedação inadequada. Esses fatores influenciam diretamente na fermentação, podendo proporcionar o desenvolvimento de microrganismos e produtos indesejáveis.

Para que seja eficiente e obtenha um resultado promissor na ensilagem é necessário compreender os principais fatores que estão envolvidos na fermentação, bem como a influência deles nas principais perdas desse processo, que interferem diretamente na qualidade da silagem. Desta forma, o objetivo desta revisão é apresentar como ocorrem as perdas no processo de ensilagem de plantas forrageiras.

\section{Metodologia}

Esta revisão é considerada qualitativa descritiva (Pereira et al., 2018), com informações publicadas em bases eletrônicas de dados (Google Scholar, Scielo, Science Direct, Scopus e Web of Sciences) e livros. Foram selecionados materiais publicados no Brasil e exterior sobre o processo de ensilagem e as principais perdas envolvidas. A busca foi norteada 
pela utilização dos termos: perdas na ensilagem, perdas por gases, perdas de matéria seca, perdas por efluentes, processo de ensilagem. Analisando os trabalhos individualmente e selecionando as partes essenciais para construir essa pesquisa.

\section{Qualidade da Silagem}

A qualidade da silagem refere-se diretamente ao sucesso ou não do processo fermentativo, juntamente com valor nutritivo constituído na silagem, pois, é uma variável que depende do processo de conservação, bem como da composição inicial da planta forrageira. O processo da ensilagem não aumenta a quantidade dos nutrientes da forragem inicial, mas estimula a manutenção do valor nutritivo. A eficiência desse processo é resultante da menor perda dos nutrientes desde a colheita da planta até o fornecimento desse alimento para os animais.

Para verificar a efetividade do processo da ensilagem as avaliações podem ser realizadas com base em alguns parâmetros, sendo eles o pH, os ácidos orgânicos e o nitrogênio amoniacal.

$\mathrm{O} \mathrm{pH}$ é um parâmetro que mensura a qualidade do processo de ensilagem, visto que nesse processo a queda do $\mathrm{pH}$ ocasionará uma redução da atividade proteolítica das enzimas da própria forragem, bem como a redução do desenvolvimento de microrganismos indesejáveis (clostrídios e enterobactérias). $\mathrm{O}$ valor do $\mathrm{pH}$ ideal que deve ser observado na silagem é entre 3,8 a 4,0 (McDonald et al., 1991).

O nitrogênio amoniacal é um produto direto das fermentações clostridiais realizadas pelas bactérias do gênero Clostridium, com a quantificação do $\mathrm{N}$-amoniacal presente na silagem pode-se classificar e enquadrar a qualidade da silagem. De acordo com Benachio (1965), silagens muito boas contem 0 a $10 \%$ de $\mathrm{N}$ amoniacal ( $\% \mathrm{~N}$ total), silagens boas de 10 a $15 \%$, silagens aceitáveis de 15 a $20 \%$, acima de $20 \%$ são silagens ruins. As silagens feitas com plantas forrageiras tropicais podem variar de 1,9 a $28,7 \%$ de $\mathrm{N}$ amoniacal do $\mathrm{N}$ total.

A fim de inibir o crescimento dos clostrídios, a produção do ácido lático realizada pelas bactérias Lactobacillus deve ser eficiente, pois a sua presença é responsável pela queda do $\mathrm{pH}$ e essa redução inibe as bactérias do gênero Clostridium, não permitindo assim a observação do nitrogênio amoniacal na silagem.

O excesso de umidade é um fator limitante, acima de $80 \%$ no momento da ensilagem, promove ações indesejáveis que afetam a qualidade do processo fermentativo (Amaral \& Nussio, 2011), ocasionando perdas de nutrientes por meio da produção de efluentes, formação de ácido butírico e degradação proteica, ou seja, esse elemento atua diretamente na fermentação do material. Desta forma, a colheita do material a ser ensilado deve ter um teor de matéria seca (MS) entre 28 a $40 \%$, valores abaixo de $28 \%$ proporcionará fermentações indesejáveis e acima de $40 \%$, haverá uma compactação inadequada (Jobim \& Nussio, 2013).

A qualidade da conservação da forragem inicia com a utilização de forrageiras com bom valor nutritivo, seguindo do emprego das tecnologias apropriadas em cada fase do processo de ensilagem, finalizando com a exclusão total do ar dentro do silo, para manter um ambiente totalmente anaeróbico, esses elementos proporcionarão um processo fermentativo ideal.

\section{Perda de Matéria Seca}

As perdas nutritivas da silagem ocorrem desde o campo até o cocho, a topografia do terreno, a altura e estrutura das plantas, o mecanismo de recolhimento e processo de picagem estão diretamente relacionadas com as perdas de matéria seca, desta forma, é necessario que o material a ser utilizado na ensilagem deve ser retirado com o teor de matéria seca ideal para que ocorra uma compactação e fermentação adequada (Jobim \& Nussio, 2013).

Para silagem de alguns tipos de gramíneas é necessário realizar a pré-murcha da planta no campo, reduzindo a quantidade de água na massa ensilada reduz a produção de efluente e melhora fermentação. (Dawson et al., 1999). Essa prática 
objetiva a redução da concentração de água na planta e consequentemente reduz as perdas provindas da presença da umidade, pois, com o menor teor de umidade no meio desfavorecem o desenvolvimento microbiano. De acordo com Rotz (2003), a realização do corte e posteriormente a secagem tem o potencial de manter a qualidade do produto e qualquer mudança nesse processo afeta a qualidade da matéria seca.

O teor de matéria seca ideal para ensilar depende da espécie da planta, um valor de referência está entre 30 a 35\% de matéria seca (Van Soest, 1994), esse parâmetro propõe evitar as perdas pela formação de efluentes e das atividades biológicas que produzem gases, água e calor, além de ajudar a promover a fermentação láctica, na qual objetiva manter o valor nutritivo do alimento.

Fatores como as altas temperaturas e a presença de chuva influenciam no teor matéria seca (Weinberg et al., 2001), logo, observar o clima durante o processo da ensilagem é essencial, para que a presença de água durante o enchimento não afete a massa, e a temperatura elevada não afete o material secando e reduzindo o valor mínimo de água na planta. Conforme Adesogan e Newman (2014) um aumento de até $12^{\circ} \mathrm{C}$ em relação a temperatura da silagem na colheita é aceitável, dessa forma, altas temperaturas e chuva causam perdas de matéria seca do material no processo de ensilagem.

O transporte da massa a ser ensilada é outro fator que provoca perdas na qualidade da silagem, principalmente sob o teor de matéria seca. Em gramíneas que necessitam realizar o emurchecimento, é preciso que o tempo desse processo seja rápido, visto que, após o corte, a planta continua respirando e consumindo energia, o que afeta os conteúdos nutritivos. Desta maneira, é importante que o momento e a duração do corte, até o emurchecimento, seja planejado em questão de tempo e logística, reduzindo essas perdas e garantir o máximo da qualidade da silagem.

Outro fator que eleva as perdas de matéria seca é o tempo na vedação do silo. Weiss et al. (2016) verificaram aumento na atividade de enterobactérias e na fermentação heterolática em silagens provindas de um silo com uma vedação demorada, observando ainda maior teor na concentração do ácido acético. Juntamente com a vedação a compactação do material deve ser realizada de forma eficiente, visto que, para ocorrer uma fermentação é necessário que o meio seja anaeróbico, ou seja, sem presença de oxigênio dentro do silo.

A presença do oxigênio estimula processos químicos, onde os nutrientes e a energia da forragem irão ser gastos, além disso, potencializa a produção de água (aumentando a umidade), dióxido de carbono, amônia livre e o aumento da temperatura (McAllister \& Hristow, 2000). Sob essa perspectiva, o processo de compactação da silagem está ligado a perda de matéria seca, logo, é necessário que essa fase seja eficiente na remoção do oxigênio da massa ensilada (McDonald et al., 1991), para que ele reduz as perdas ocasionadas por uma realização inadequada.

A quantidade da perda de matéria seca da fermentação depende, sobretudo das espécies microbianas dominantes no ambiente e dos substratos fermentados. Pahlow et al. (2003) citaram que as principais perdas são decorrentes da atividade de enterobactérias, clostrídios e leveduras. Dentre eles o destaque é das bactérias ácido láticas heterofermentativas, que fermentam glicose e produzem dióxido de carbono, reduzindo o teor de matéria seca e energia bruta da silagem. As leveduras também interferem nessa perda, pois na estabilização do processo fermentativo tendem influenciar de forma negativa (Pedroso et al., 2005).

A temperatura dentro do silo influência no crescimento dos microrganismos. De acordo com Yamamoto et al. (2011), as bactérias ácido láticas crescem entre 27 a $38^{\circ} \mathrm{C}$. Para a silagem de milho observa-se uma temperatura média de $40^{\circ} \mathrm{C}$ dentro do silo e menor presença de leveduras, em torno de 82 dias de armazenamento (Kim \& Adesogan, 2006). Sob essa perspectiva, Weiss et al. (2016) observaram que as silagens seladas a temperaturas mais elevadas reduziram a presença de leveduras.

A silagem de milho é considera padrão, por preencher os requisitos para a confecção de uma silagem de boa qualidade, contendo um teor de matéria seca entre 30 e 35\%, no mínimo 3\% de carboidratos solúveis, possui baixo poder tampão, além de proporcionar boa fermentação microbiana (Kiyota et al., 2011). Entretanto, a silagem de cana de açúcar 
possui características que afetam as perdas de matéria seca, nas quais estão correlacionadas ao padrão de fermentação, devido à alta produção de etanol e elevado desaparecimento de carboidratos solúveis, ocasionando também uma redução no valor nutritivo e elevada produção de efluente (Cavali et al., 2010).

A quantificação da perda de matéria seca nesse processo pode ser realizada pelos nutrientes contidos no efluente, calor de catabolismo de nutrientes por células vivas e pelos subprodutos gasosos do catabolismo de nutrientes (Gordon, 1967). A metodologia de Neumann (2006) visa a quantificação das perdas por meio da diferença de gradientes de concentração entre o material original e o material após a abertura do silo. Outra metodologia descrita por Schmidt (2006) calcula a perda total de matéria seca pela diferença entre os pesos brutos de matéria seca inicial e final do silo. Desta forma, a base para quantificar a perda de matéria seca no processo da ensilagem é por meio da diferença entre os pesos.

Cada espécie tem teores de perda de matéria seca diferentes, por exemplo, no milho pode ser observado teores entre 17,59\% para silagem com grão pastoso e 5,77\% para silagem do grão duro (Marafon et al., 2015). Para cana de açúcar observa-se uma perda média de 13,9 e 12,6\% (Amaral et al., 2009; Schmidt et al., 2011), já em silagens feitas com capim as perdas variam de acordo com a espécie, variando entre 9 e $14 \%$, para o tifton e a estrela africana branca, respectivamente (Quaresma et al., 2010).

Além das perdas de matéria seca ocasionarem redução na qualidade nutritiva no que diz respeito a silagem, ela interfere na qualidade nutritiva para o consumo animal, na qual, essas perdas elevam proporcionalmente os constituintes fibrosos e, consequentemente, reduzem a digestibilidade da matéria seca (Carvalho et al., 2014).

\section{Perda por Efluente}

Para minimizar as perdas por efluente, é importante que o teor de matéria seca seja correto, ou seja, no momento da ensilagem a planta deve ter em média de 35\% de MS. A presença de umidade aumenta a produção de efluente, e o processo de ensilagem, desde a forma de colheita, processamento, estádio de maturação da planta, dentre outros, contribuem para a produção de efluente. Uma maneira de evitar as perdas por efluente é realizar a murcha na planta antes de ensilar, para que os nutrientes não lixiviem (França et al., 2014).

O efluente da silagem contém compostos orgânicos, sendo eles: açúcares, ácidos orgânicos e proteínas (McDonald et al., 1991), o que constitui uma perda nutritiva-para o processo de conservação e para a qualidade da silagem. Os processos de conservação de forragem convivem rotineiramente com perdas de nutrientes de diversas magnitudes, essas perdas ocorrem ao longo do tempo dentro do silo, a presença desses compostos é indesejável, pois o efluente interfere negativamente no processo fermentativo, contribuindo para o crescimento de bactérias do gênero Clostridium.

O volume da produção de efluente varia de acordo com a quantidade de matéria seca, tipo de silo, faixa de corte, qualidade da planta forrageira, tamanho das partículas e a presença de aditivos. A depender da quantidade desse volume, o efluente pode causar graves problemas ambientais, devido a sua alta demanda bioquímica de oxigênio (BOD) (até $50.000 \mathrm{mg}$ O2 1-1) (Weinberg \& Ashbell, 2003).

Dentre os fatores que contribuem para o aumento da produção de efluente, o tamanho da partícula se torna um ponto chave para evitar essas perdas por efluente, devido a sua alta relação com a anaerobiose do sistema. Quando as partículas são de um tamanho apropriado, entre 3 a $5 \mathrm{~cm}$, há uma rápida estabilidade da anaerobiose, no entanto, quando a partícula é muito pequena o processo de fermentação resulta em alta produção de efluente, ocorrendo perdas significativas na qualidade da silagem (Demarquilly et al., 1998).

As perdas por efluente podem ser quantificadas através das equações descritas por Jobim et al. (2007), baseado na diferença dos pesos. De acordo com Marafon et al. (2015), a presença de umidade na silagem no grão do milho, aumentou as perdas na matéria seca e na produção de efluente. 


\section{Perda por Gases}

A principal perda gerada no processo de ensilagem é por meio da produção do dióxido de carbono, consequência do ambiente anaeróbico e da fermentação realizada pelos microrganismos nos açúcares e ácidos orgânicos. Essas perdas por gases podem chegar de 2 a 4\% e estão associadas com todo o ambiente dentro do silo (Zimmer, 1980). A produção do gás carbônico é decorrente da respiração da planta que utiliza o oxigênio residual, de infiltrações ou até mesmo proveniente de bactérias anaeróbias, que realizam fermentações indesejáveis (Fernandes et al., 2016).

Alguns trabalhos demonstram as perdas por gases em silagens (Negrão et al., 2020; Pinedo et al., 2020; Marques et al., 2021). De acordo Gandra et al. (2018), que ao trabalharem com adição de quitosana na silagem com aditivo antimicrobial, observaram aumento nas perdas por gases e inferiram que esta perda está relacionada com o aumento da presença dos microrganismos. Souza et al. (2018) confrontaram a redução do pH da silagem com o teor de carboidratos não fibrosos, observando aumento nas perdas por gases das silagens estudadas. É evidente que as perdas que ocorrem por meio da produção de gases são influenciadas por diversos fatores no processo da ensilagem.

A produção de gases no processo da ensilagem interfere diretamente na perda de matéria seca, pois a perda de carboidratos solúveis na forma de gases tem como consequência a produção de água, reduzindo o teor de matéria seca o que promove a sua perda (Balieiro Neto et al., 2009). Além disso, o teor de ácido lático influencia positivamente na redução das perdas por gases, pois a fermentação da glicose com produção de ácido lático não gera produção de gás carbônico (Lorenzo \& O'Kiely, 2008). As fermentações láticas reduzem essas percas devido à relação com a alta produção do ácido lática sob a produção do ácido acético e butírico.

A quantificação da perda de gases é importante para verificar o processo fermentativo e esboçar a atuação dos microrganismos dentro do silo. Em silagem de milho, observaram uma produção de gás entorno de 424 litros por tonelada (Schmidt et al., 2012). Essas perdas por gases podem ser calculadas com equações descritas por Jobim et al. (2007) ou por meio da diferença entre pesos dos silos experimentais.

\section{Deterioração Aeróbica}

A deterioração aeróbia é caracterizada pela entrada de ar no silo, como consequência, há multiplicação de microrganismos aeróbios e o consumo dos compostos energéticos presentes na silagem. O oxigênio penetra na massa ensilada, que com o seu movimento proporciona porosidade do material, essa ação reduz a qualidade da silagem desde a exposição da silagem no painel do silo até o cocho (Pahlow et al., 2003).

A temperatura é um dos elementos que provoca a deterioração da massa ensilada, em consequência da ação prolongada é a promoção do crescimento das leveduras e fungos filamentosos (McDonald et al., 1991), o desenvolvimento desses microrganismos ocorre quando há picos termais ocasionados pela exposição da massa ao ar. O oxigênio penetra na massa ensilada e os microrganismos aeróbicos começam a se desenvolverem devido à disponibilidade dos substratos solúveis.

Neste sentido, as leveduras são as iniciadoras do processo de deterioração aeróbica, consumindo os carboidratos que elevam a temperatura e $\mathrm{pH}$ da silagem, principalmente aquelas que consomem o lactato (Pahlow et al., 2003).

Os fungos são os principais microrganismos relacionados à deterioração da silagem exposta ao ar, destacando-se as leveduras, e as bactérias do gênero Bacillus (Woolford, 1984), podendo permanecer inativas dentro do silo até a exposição da massa ensilada ao oxigênio. Esses microrganismos utilizam substratos derivados diretamente da forragem ou indiretamente da fermentação para o seu desenvolvimento.

As silagens mais propicias a deterioração aeróbia são aquelas com maior teor de carboidrato residual, por terem sido inoculadas ou intensivamente emurchecidas. A utilização de alimentos secos para equilibrar o teor de água da massa ensilada 
proporciona uma matéria seca adequada, reduzindo a atividade de água e potencializando o atraso no início da deterioração do material, devido ao sequestro de água pelo o material seco (Amaral et al., 2009).

Para obter uma silagem de qualidade é necessário observar esses fatores a fim de prevenir para que ocorra em mínima escala, devendo haver atenção em todas as etapas do processo da ensilagem, principalmente no momento da compactação, para remover máximo de o ar possível e obter um melhor controle desse processo. Visto que, a deterioração aeróbia contribui com as perdas de matéria seca e do valor nutritivo, influenciando negativamente no desempenho produtivo dos animais (Bernardes et al., 2007).

\section{Considerações Finais}

Para a obtenção de uma silagem de qualidade é necessário que seja observada onde ocorrem as principais perdas, visando a interferência para melhorar caso seja necessário e obter como resultado uma silagem de alta qualidade. As perdas podem ocorrer na matéria seca, na produção de efluente e gases, além da ação do oxigênio no momento da abertura do silo com a deterioração aeróbia. Há diversas maneiras para tentar reduzir essas perdas, desde o campo até o fornecimento ao animal. A atenção às etapas do processo da ensilagem faz toda a diferença para ter uma silagem de excelente qualidade, expressando no sistema produtivo de carne e/ou leite a ser utilizado.

Pesquisas que verificam as perdas que ocorrem na ensilagem são essenciais para compreender todos os fatores que estão envolvidos nesse processo e os seus efeitos. Desta forma, é necessario que seja realizados estudos sobre os parâmetros fermentativos de diferentes tipos de silagem e como esses elementos estão correlacionados com as suas perdas. A realização desses estudos aperfeiçoa e contribui para a construção de um conhecimento sólido desse processo.

\section{Referências}

Adesogan, A. T., \& Newman, Y. C. (2014). Silage harvesting, storing and feeding. IFAS Extension, University of Florida, Gainesville. Recuperado de http://edis.ifas.ufl.edu/pdffiles/AG/AG18000.pdf.

Amaral, R. C., \& Nussio, L. G. (2011). Fungos e micotoxinas em silagens: In: Simpósio sobre produção e utilização de forragens conservadas, Anais..., 221250 .

Amaral, R. C. D., Pires, A. V., Susin, I., Nussio, L. G., Ferreira, E. M., \& Gentil, R. S. (2009). Cana-de-açúcar in natura ou ensilada com e sem aditivos químicos: estabilidade aeróbia dos volumosos e das rações. Revista Brasileira de Zootecnia, 38(10), 1857-1864. doi: https://doi.org/10.1590/S151635982009001000001 .

Balieiro Neto, G., Siqueira, G. R., Nogueira, J. R., Reis, R. A., Roth, A. P. D. T. P., \& Roth, M. D. T. P. (2009). Perdas fermentativas e estabilidade aeróbia de silagens de cana-de-açúcar aditivadas com cal virgem. Revista Brasileira de Saúde e Produção Animal, 10(1), 24-33. Recuperado: file:///C:/Users/agrob/Downloads/39983-144068-1-PB.pdf.

Benachio, S. (1965). Niveles de melaza en silo experimental de milho crillo (Sorghum vulgare). Agronomia Tropical, 14, $291-297$.

Bernardes, T. F., Reis, R. A., Siqueira, G. R., Amaral, R. C. D., \& Pires, A. J. V. (2007). Estabilidade aeróbia da ração total e de silagens de capim-marandu tratadas com aditivos químicos e bacterianos. Revista Brasileira de Zootecnia, 36(4), 754-762. doi: https://www.scielo.br/pdf/rbz/v36n4/02.pdf.

Carvalho, F. A. L. D., Queiroz, M. A. Á., Silva, J. G. D., \& Voltolini, T. V. (2014). Características fermentativas na ensilagem de cana-de-açúcar com maniçoba. Ciência Rural, 44(11), 2078-2083. doi: http://dx.doi.org/10.1590/0103-8478cr20131471.

Cavali, J., Pereira, O. G., Valadares Filho, S. D. C., Porto, M. O., Fernandes, F. E. P., \& Garcia, R. (2010). Mixed sugarcane and elephant grass silages with or without bacterial inoculant. Revista Brasileira de Zootecnia, 39(3), 462-470. doi: http://dx.doi.org/10.1590/S1516-35982010000300003.

Dawson, L. E. R., Ferris, C. P., Steen, R. W. J., Gordon, F. J., \& Kilpatrick, D. J. (1999). The effects of wilting grass before ensiling on silage intake. Grass and Forage Science, 54(2), 237-247.doi: 10.1046 / j.1365-2494.1999.00176.x.

Demarquilly, C., Dulphy, J. P., \& Andrieu, J. P. (1998). Valeurs nutritive et alimentaire des fourrages selon les techniques de conservation: foin, ensilage, enrubannage. Fourrages (Versailles), (155), 349-369. Recuperado: file:///C:/Users/agrob/Downloads/155-DEMARQUILLY.pdf.

Fernandes, G. F., Evangelista, A. F., \& Borges, L. (2016). Potencial de espécies forrageiras para produção de silagem: revisão de literatura. Revista Eletrônica Nutri Time, 13(3), 4652-4656. Recuperado: classroom.google.com/u/1/c/MTE4Njc0Nzg1ODc0.

França, A. M. S., Ferreira, I. C., Hermisdorff, Í. D. C., Mendonça, E. P., Fernandes, E. D. A., \& Rossi, D. A. (2014). Dinâmica química, microbiológica e física da silagem de farelo úmido de glúten de milho. Ciência Rural, 45(4), 684-689. doi: http://dx.doi.org/10.1590/0103-8478cr20140716. 
Gandra, J. R., Takiya, C. S., Del Valle, T. A., Oliveira, E. R., Goes, R. H. T. B., Gandra, E. R. S., Batista, J. D. O., \& Araki, H. M. C. (2018). Soybean wholeplant ensiled with chitosan and lactic acid bacteria: Microorganism counts, fermentative profile, and total losses. Journal of dairy science, 101(9), 7871-7880. doi: https://doi.org/10.3168/jds.2017-14268.

Gordon, C. H. (1967). Storage losses in silage as affected by moisture content and structure. Journal of dairy science, 50(3), 397-403. doi: https://doi.org/10.3168/jds.S0022-0302(67)87434-4.

Jobim, C. C., Nussio, L. G., Reis, R. A., \& Schmidt, P. (2007). Avanços metodológicos na avaliação da qualidade da forragem conservada. Revista Brasileira de Zootecnia, 36, 101-119. doi: http://dx.doi.org/10.1590/S1516-35982007001000013.

Jobim, C. C., \& Nussio, L. G. (2013). Princípios básicos da fermentação na ensilagem. In: Reis, R. A., Bernardes, T. F.; Siqueira, G. R. Forragicultura: Ciência, tecnologia e gestão dos recursos forrageiros. Jaboticabal-SP: FUNEP, 649-660.

Kim, S. C., \& Adesogan, A. T. (2006). Influence of ensiling temperature, simulated rainfall, and delayed sealing on fermentation characteristics and aerobic stability of corn silage. Journal of Dairy Science, 89(8), 3122-3132. doi: https://doi.org/10.3168/jds.S0022-0302(06)72586-3.

Kiyota, N., Vieira, J. A. N., Yagi, R., \& Lugão, S. M. B. (2011). Silagem de milho na atividade leiteira do sudoeste do Paraná: do manejo de solo e de seus nutrientes á ensilagem de planta inteira e grãos úmidos. Londrina: IAPAR, $124 \mathrm{p}$.

Lorenzo, B. F., \& O'Kiely, P. (2008). Alternatives to formic acid as a grass silage additive under two contrasting ensilability conditions. Irish Journal of Agricultural and Food Research, 47(2), 135-149. Recuperado: https://core.ac.uk/reader/45656390.

Marafon, F., Neumann, M., Carletto, R., de Lima Wrobel, F., Mendes, E. D., Spada, C. A., \& Faria, M. V. (2015). Características nutricionais e perdas no processo fermentativo de silagens de milho, colhidas em diferentes estádios reprodutivos com diferentes processamentos de grãos. Semina: Ciências Agrárias, 36(2), 917-931. doi: 10.5433/1679-0359.2015v36n2p917.

Marques, K.O., Jakelaitis, A., Guimarães, K. C., \& Pereira, L. S. (2021). Perfil agronômico, fermentativo e bromatológica da silage obtida do consórcio entre milho e soja. Research, Society and Development, 10(1). doi: http://dx.doi.org/10.33448/rsd-v10i1.11925.

McAllister, T. A. \& Hristov, A. N. (2000). The fundamentals of making good quality silage. Advences Dairy Technol, 12, 381-399. Recuperado: https://www.yumpu.com/en/document/read/49887728/the-fundamentals-of-making-good-quality-silage.

McDonald, P., Henderson, A. R., \& Heron, S. J. E. (1991). The biochemistry of silage. Chalcombe publications, Bucks, UK.

Negrão, F. M., Zanine, A. M., Silva Filho, A. S., Silva, A. R., Santos, R. M., Caldeira, F. H. B., Lins, T. O. J. A., Ciríaco, A. P., Freiria, L. B., \& Reis, R. H. P. (2020). Perdas e composição química das silagens de capim-piatã com inclusão do resíduo de feijão. Research, Society and Development, 9(7). doi: http://dx.doi.org/10.33448/rsd-v9i7.4753.

Neumann, M. (2006). Efeito do tamanho de partícula e da altura de colheita das plantas de milho (Zea mays L.) sobre perdas, valor nutritivo de silagens e desempenho de novilhos confinados (Tese). Universidade Federal do Rio Grande do Sul, Porto Alegre, RS.

Pahlow, G., Muck, R. E., Driehuis, F., Elferink, S. J. O., \& Spoelstra, S. F. (2003). Microbiology of ensiling. Silage science and technology, 42, 31-93. doi: https://doi.org/10.2134/agronmonogr42.c2.

Pedroso, A. D. F., Nussio, L. G., Paziani, S. D. F., Loures, D. R. S., Igarasi, M. S., Coelho, R. M., Packer, H. I., Horii, J., \& Gomes, L. H. (2005). Fermentation and epiphytic microflora dynamics in sugar cane silage. Scientia Agricola, 62(5), 427-432. Doi: https://doi.org/10.1590/S010390162005000500003 .

Pereira, A. S., Shitsuka, D. M., Parreira, F. J. \& Shitsuka, R. (2018). Metodologia da pesquisa científica. [e-book]. Santa Maria. Ed. UAB/NTE/UFSM. Recuperado de: https://repositorio.ufsm.br/bitstream/handle/1/15824/Lic_Computacao_Metodologia-Pesquisa-Cientifica.pdf?sequence=1 .

Pinedo, L. A., Oliveira, P. V. C., Firmino, S. S., Ribeiro, A. A., Santos, B. R. C., Amorim, D. S., Chacón, S. G., \& Codognoto, L. C. (2020). Parâmetros bromatológicas e fermentativos da silage de capim elefante aditivado com subproduto de cupuaçu. Research, Society and Development. 9(9). doi: http://dx.doi.org/10.33448/rsd-v9i9.7665.

Quaresma, J. P. S., Abreu, J. G. D., Almeida, R. G. D., Cabral, L. D. S., Oliveira, M. A. D., \& Rodrigues, R. C. (2010). Recuperação de matéria seca e composição química de silagens de gramíneas do gênero Cynodon submetidas a períodos de pré-emurchecimento. Ciência e Agrotecnologia, 34(5), 12321237. doi: https://doi.org/10.1590/S1413-70542010000500022.

Rotz, C. A. (2003). How to maintain forage quality during harvest and storage. In Western Canadian Dairy Seminar, 227-236.

Schmidt, P. (2006). Perdas fermentativas na ensilagem, parâmetros digestivos e desempenho de bovinos de corte alimentados com rações contendo silagens de cana-de-açúcar (Tese). Escola Superior de Agricultura "Luiz de Queiroz", Universidade de São Paulo, Piracicaba, SP. Recuperado: https://www.teses.usp.br/teses/disponiveis/11/11139/tde-06102006-170541/publico/PatrickSchmidt.pdf.

Schmidt, P., Rossi Junior, P., Junges, D., Dias, L. T., Almeida, R. D., \& Mari, L. J. (2011). Novos aditivos microbianos na ensilagem da cana-de-açúcar: composição bromatológica, perdas fermentativas, componentes voláteis e estabilidade aeróbia. Revista Brasileira de Zootecnia,40(3), 543-549. doi: https://doi.org/10.1590/S1516-35982011000300011

Schmidt, P., Novinski, C. O., Carneiro, E. W., \& Bayer, C. (2012). Greenhouse gas emissions from fermentation of corn silage. In: XVI International Silage Conference. Hämeenlinna, Finland. Recuperado: https://www.isfqcbrazil.com.br/proceedings/2013/73.pdf.

Souza, C. M., Oliveira, R. L., Voltolini, T. V., Menezes, D. R., dos Santos, N. J. A., Barbosa, A. M., Silva, T. M., \& Bezerra, L. R. (2018). Lambs fed cassava silage with added tamarind residue: silage quality, intake, digestibility, nitrogen balance, growth performance and carcass quality. Animal Feed Science and Technology, 235, 50-59. Doi: https://doi.org/10.1016/j.anifeedsci.2017.11.007. 
Research, Society and Development, v. 10, n. 5, e8910514660, 2021

(CC BY 4.0) | ISSN 2525-3409 | DOI: http://dx.doi.org/10.33448/rsd-v10i5.14660

Teixeira, F. A.; Amin, W. G.; \& Paula, M. S. (2009). Avaliação da produtividade das silagens de girassol, milho, sorgo e milheto em diferentes espaçamentos Nucleus, 6(2), 69-81. Recuperado: file:///C:/Users/agrob/Downloads/Dialnet-AvaliacaoDaProdutividadeDasSilagensDeGirassolMilho-4034562.pdf.

Van Soest, P. J. (1994). Nutritional ecology of the ruminant. Cornell university press. New York. 476p.

Weinberg, Z. G., \& Ashbell, G. (2003). Engineering aspects of ensiling. Biochemical Engineering Journal, 13 (2-3), 181-188. doi: https://doi.org/10.1016/S1369-703X(02)00130-4.

Weinberg, Z. G., Szakacs, G., Ashbell, G., \& Hen, Y. (2001). The effect of temperature on the ensiling process of corn and wheat. Journal of applied microbiology, 90(4), 561-566. doi: https://doi.org/10.1046/j.1365-2672.2001.01276.x.

Weiss, K., Kroschewski, B., \& Auerbach, H. (2016). Effects of air exposure, temperature and additives on fermentation characteristics, yeast count, aerobic stability and volatile organic compounds in corn silage. Journal of dairy science, 99(10), 8053-8069. doi: https://doi.org/10.3168/jds.2015-10323.

Woolford, M. K. (1984). The silage fermentation. New York: Marcel Dekker. 305p.

Yamamoto, Y., Gaudu, P., \& Gruss, A. (2011). Oxidative stress and oxygen metabolism in lactic acid bacteria. Lactic Acid Bacteria and Bifidobacteria: Current Progress in Advanced Research, 91-102. Norfolk, UK.

Zimmer, E. (1980). Efficient silage systems. In Occasional symposium-British Grassland Society._Reading, UK. 